\title{
National freight multimodal transport system: the Italian project for the ITS integration
}

\author{
R. D. Dominicis ${ }^{1}$, F. Russo ${ }^{2} \&$ A. Quattrone ${ }^{2}$ \\ ${ }^{I}$ Department of Mathematics and Statistics, \\ Federico II University of Naples, Italy \\ ${ }^{2}$ Department of Computer Science, Mathematics, Electronics and \\ Transports, Mediterranean University of Reggio Calabria, Italy
}

\begin{abstract}
The analysis of the transport sector in Italy highlights serious deficiencies in infrastructure, management and organization and, in general, inadequate quality and competitiveness of the service offered. In order to support the solving of these critical issues, under the European ITS framework, as executor of the Italian Ministry of Transport, UIRNet $S p A$ is creating in Italy the first multi-sided National Logistic ITS Platform (PLN) to make the national freight multimodal transport system efficient, reliable, safe, and eco-conscious using pervasive technology and collaboration among actors. This paper provides an overview of the integrated PLN, with emphasis on the IT services supplied.

Keywords: national ITS, freight transport, logistics.
\end{abstract}

\section{Introduction}

Freight transport and logistics plays a fundamental role in the economy of every country. The index of inland freight transport in the EU-27 grew continuously between 2000 and 2007. In 2009, road transport made up over half of freight transport in twenty five Member States [1]. Table 1 shows the percentage shared of road freight in total inland freight transport, expressed in tonne-kilometres (tkm). Moreover freight transport system has had to adapt to accommodate new business concepts (i.e. business-to-business and business-to-customer e-commerce) and freight movement is becoming more complex and increasingly time critical due to just-in-time delivery and the globalization of the world economy. 
Table 1: $\quad$ Modal split of freight transport $-\operatorname{road} \%$ in total inland freight tonne-km - source of data: [4].

\begin{tabular}{|c|c|c|c|c|c|c|c|c|}
\hline GEO/TIME & 2002 & 2003 & 2004 & 2005 & 2006 & 2007 & 2008 & 2009 \\
\hline European Union (27) & 75.3 & 75.7 & 75.9 & 76.4 & 76.2 & 76.2 & 76,2 & 77,5 \\
\hline European Union (25) & 75.8 & 76.1 & 76.4 & 76.7 & 76.4 & 76.4 & 76,5 & 78,1 \\
\hline Belgium & 77.5 & 76.5 & 74.9 & 72.4 & 71.1 & 69.7 & 68,5 & 72,9 \\
\hline Bulgaria & 62.9 & 61.7 & 66.9 & 70.8 & 69 & 70 & 66,9 & 67,4 \\
\hline Czech Republic & 73.3 & 74.5 & 75.2 & 74.4 & 76.1 & 74.7 & 76,7 & 77,8 \\
\hline Denmark & 92.1 & 92.1 & 90.9 & 92.2 & 91.8 & 92.2 & 91,3 & 90,8 \\
\hline Germany & 66.3 & 67.0 & 66.1 & 66 & 65.9 & 65.7 & 65,5 & 67,0 \\
\hline Estonia & 30.3 & 29.1 & 32.7 & 35.4 & 34.7 & 43.2 & 55,3 & 47,3 \\
\hline Ireland & 97.1 & 97.5 & 97.7 & 98.3 & 98.8 & 99.3 & 99,4 & 99,4 \\
\hline Greece & : & 97.7 & & 97.5 & 98.1 & 97.1 & 97,3 & 97,8 \\
\hline Spain & 94.1 & 94.3 & 94.9 & 95.2 & 95.4 & 95.9 & 95,9 & 96,6 \\
\hline France & 77.8 & 78.8 & 79.9 & 80.5 & 80.9 & 80.9 & 80,7 & 81,0 \\
\hline Italy & 90.4 & 89.5 & 89.8 & 90.3 & 88.5 & 87.6 & 88,3 & 91,0 \\
\hline Cyprus & 100 & 100 & 100 & 100 & 100 & 100 & 100 & 100 \\
\hline Latvia & 29.2 & 27.5 & 28.4 & 29.8 & 39 & 41.9 & 38,7 & 30,2 \\
\hline Lithuania & 52.3 & 50 & 51.3 & 56.1 & 58.4 & 58.5 & 58,0 & 59,9 \\
\hline Luxembourg & 90.7 & 92 & 91.2 & 92.3 & 91.5 & 93.8 & 94,2 & 94,6 \\
\hline Hungary & 65.5 & 66.6 & 65.9 & 69.2 & 71.6 & 74.5 & 74,7 & 78,8 \\
\hline Malta & 100 & 100 & 100 & 100 & 100 & 100 & 100 & 100 \\
\hline Netherlands & 63.3 & 64.6 & 64.7 & 63.6 & 63.1 & 59.4 & 59,9 & 63,4 \\
\hline Austria & 65.8 & 67.4 & 65.6 & 64.1 & 63.2 & 60.9 & 58,6 & 59,5 \\
\hline Poland & 62.2 & 64.0 & 66.1 & 69.0 & 70.4 & 73.5 & 75,9 & 80,5 \\
\hline Portugal & 93.1 & 93 & 94.7 & 94.6 & 94.9 & 94.7 & 93,9 & 94,3 \\
\hline Romania & 57.3 & 62.4 & 60.8 & 67.3 & 70.5 & 71.3 & 70,2 & 60,0 \\
\hline Slovenia & 70.0 & 70.0 & 74.1 & 77.3 & 78.2 & 79.2 & 82,2 & 84,0 \\
\hline Slovakia & 58.7 & 62.1 & 65.4 & 70.3 & 68.8 & 71.8 & 73,8 & 77,9 \\
\hline Finland & 76.6 & 75.3 & 76 & 76.5 & 72.8 & 73.9 & 73,3 & $:$ \\
\hline Sweden & 65.6 & 64.5 & 63.9 & 64 & 64.2 & 63.6 & 64,7 & 62,5 \\
\hline United Kingdom & 89.7 & 89.8 & 87.8 & 87.8 & 85.8 & 86.6 & 86,5 & 86,7 \\
\hline Iceland & 100 & 100 & 100 & 100 & 100 & 100 & 100 & 100 \\
\hline Norway & 85.1 & 86.3 & 86.0 & 85.2 & 85.3 & 84.7 & 85,0 & 83,4 \\
\hline Croatia & 76.4 & 76.1 & 76.7 & 76 & 74.8 & 74 & 72,7 & 73,7 \\
\hline Macedonia & 92.3 & 93.6 & 92.6 & 91.3 & 93.1 & 88.4 & 84,3 & $:$ \\
\hline Turkey & 95.5 & 94.6 & 94.4 & 94.8 & 94.9 & 94.9 & . & 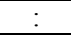 \\
\hline
\end{tabular}

Italy also presents a high road share of freight transport and a large number (approximately 4,6 million) of commercial vehicles registered in 2010 [2]. Moreover, the logistics emerge as an important component of the Italian economic system, worth over $€ 100 \mathrm{mld}$ (in 2009 ), approximately $7.0 \%$ of GDP, a value higher than the EU average $(6.8 \%)$ which translates into an Italian chain extra-cost, which penalize the competitiveness of Italian companies: Overall, Italy has a cost of traditional logistics (including transport operations) major of $11 \%$ above the European average, with a charge for the system estimated at about $€ 12$ mld [3].

Consequently, domestic economic competitiveness is significantly affected by the reliability of truck operations. 
In truck operations arrival time reliability is critical because arriving late or even too early at a destination may incur a penalty. For example, if a truck arrives at an intermodal terminal later than its scheduled arrival time for the connecting transportation mode (train, ship, or airplane), the truck may miss its cargo's connection and require rescheduling or be forced to reroute its trip plan [5]. As well early arrival may also create problems such as air pollution from increased idling time, increased traffic congestion in the surrounding area of the terminal, traffic accidents as a result of congestion/illegal parking, and truck driver inefficiency. In most cases these actions incur additional cost borne by the truck operator decreasing terminal accessibility [6].

Furthermore the analysis of the transport sector in Italy highlights serious deficiencies in infrastructure, management and organization and, in general, inadequate quality and competitiveness of the service offered.

One of the main critical elements is the business structure of Italian operators in the sector that - although with peaks of excellence - is substantially weaker. The Italian private transport company, especially in the freight and logistics sector, is in a subordinate position compared with foreign competitors that are far more structured by size, business skills and levels of organizational and technological innovation.

It's likely to provide that in the absence of appropriate measures, foreign companies much more competitive and who have already absorbed major Italian companies, occupying ever increasing share of the Italian market. If we add to the fragmentation of the sector in the specific field of road transport and size medium/small, the problem becomes very negative.

The Italian chain extra-cost [3], linked to the other considerations increase the importance of understanding and modelling the behaviour of truck drivers and other actors on the supply chain in order to identify solutions to improve reliability, efficiency, safety and security and sustainability of freight transport and logistics.

These solutions can be pursued through two different ways:

1. the development of new material infrastructure;

2. the use of transport telematics to improve efficiency of the existing infrastructures and transport services while reducing its negative impacts using techniques based on information, communications, control and monitoring.

Intelligent Transport Systems (ITS), as well known, can allow to solve the cited issues significantly contributing to a cleaner, safer and more efficient transport system [7].

This scenario identifies in the info-telematics the response to market needs, but it is unthinkable that the individual actors organizes itself with high-level technological tools that allow each of them to be more productive and competitive.

The necessary and rapid development of ITS cannot be left to chance of individual entrepreneurial action, as this may have an inordinate development, expanded over time, high-cost and non-uniform and non-interoperable with all 
other public and private entities that compose the total transport and logistics chain.

It is necessary to eliminate the obstacles to the ITS development, coordinated implementation and diffusion, creating the basic conditions for the market, an adapted context of development and a framework of unitary reference.

A new legal framework (Directive 2010/40/EU [8], Frame Architecture [9], ITS Action Plan [10]) was recently adopted to accelerate the deployment of these innovative transport technologies across Europe. It aims to establish interoperable and seamless ITS services while leaving Member States the freedom to decide which systems to invest in.

Under this guideline framework, as executor of Italian Ministry of Transport, UIRNet SpA is creating in Italy the first multi-sided National Logistic ITS Platform $(P L N)$ to make the freight transport system efficient, reliable, safe, and eco-conscious using pervasive technology and collaboration among actors.

The UIRNet's initiative can produce significant benefits and potential savings, compared with a limited investment. Furthermore the introduction of mature systems and data-telecommunication services onto the market will encourage new opportunities in journey planning and collecting information, distribution both nationally and abroad of information relating to road conditions, traffic, accidents, diversion due to accidents, monitoring of empty vehicles and those carrying hazardous goods and optimized management of haulage fleets not to mention assistance to drivers in transit and in case of emergency.

Therefore, the ITS integration is topical for the national freight multimodal transport system, due its capability to add value to it and to allow the interchange among different transport mode (in particular the road-railway co-modality).

This paper provides an overview of the integrated PLN, developed by UIRNet in the Italian context of the multimodal freight transport and logistics system. Starting from the minimum set of user need to be covered in order to solve the previous cited critical aspects, the framework architecture and services supplied by the $P L N$ are explored, with emphasis on the experimentations already under way and planned for the near future.

\section{State of the art}

In spite of the importance of freight transport, only in the last fifteen years the research devotes itself to this field. The most investigate topic are the national freight transport and the choice behaviour of truck drivers [11-17]. Recently Russo and Vitetta [18] have defined a model and a procedure to solve it that allows transport models to be calibrated to simulate present and hypothetical scenario configurations prior to scenario implementation or within before-after planning procedures.

In recent years the research has focused its efforts on the application of new technologies to the integrated transport system [7], such as the development of the Trans-European Transport Networks (TEN-T) and of the EASYWAY Program (2007-2013) financed by the European Commission, or of the 
information platform for European cargo railways - CroBIT [19, 20], but little has been done in the field of National Road Freight Transport and Logistics with focus on ITS interoperability.

All over the industrialized world, the skills with regard to transport were defined in the pre-telematic years. The problem of ensuring coordination of all the systems involved, and for all subsystem components of each system, did not exist. Much has been written on the telematic network, distinguishing different levels of architecture (logical, physical, data-link, application etc.) [21]. This segmentary approach requires the definition of standards that allow the various levels to communicate between themselves.

This is true, in particular, at national level because of the great number of different actors involved:

- $\quad$ public decision makers, that are interested in improving traffic management and minimizing environmental impacts;

- couriers and shippers that are interested in minimizing travel time and costs, adjusting themselves to the time windows defined by the decision makers and obtaining more information about the accessibility;

- retailers and vendors that are interested in obtaining the freight arrival just in time and minimizing the time related to reverse logistics;

- users that are interested in improving their accessibility also to the added value services (e.g. e-commerce).

In order to improve the communication among these actors and therefore the efficiency of the national freight transport and logistics, is topical to define homogenous structures for the ITS systems used by different actors and a common framework of reference.

The European Commission, that intends to facilitate the diffusion of the intelligent transport systems and to create an only market for ITS has delivered in September 2000 the first version of the European ITS Framework Architecture, often now known as the FRAME Architecture [9]. FRAME supplies a platform of reference for development of the products and ITS services in Europe. The adoption of the FRAME instrument during the design phase concurs to the standardization of transport telematic systems and the possibilities for the actors of all the mobility fields to use a common language about ITS. At national level, on the basis of the FRAME results, several EU Member State have realized their ITS Architecture specifications: in Italy, in September 2001, the Italian Ministry of Infrastructure and Transport promoted the ARTIST Project (ARchitettura Telematica Italiana per il Sistema dei Trasporti) [22].

UIRNet starting from the European/Italian Architecture User Needs, and integrating them with other user needs related to specific requirement of the Italian logistics stakeholder (on the basis of several key-users' sound indications), has defined the basic functionalities of the National Logistic Platform. 
In particular, the FRAME/ARTIST User Need group considered as a starting point by UIRNet is the 9.5 Commercial Fleet Management that consists of the following sub-groups (table 2) that support fleet and freight operations for all sizes of operator, including single vehicle companies.

Table 2: $\quad$ System services overview.

\begin{tabular}{|l|l|}
\hline \multicolumn{1}{|c|}{ Topic ID } & \\
\hline 9.5 .1 & Road Freight Management \\
\hline 9.5 .2 & Road Freight Fleet Management \\
\hline 9.5 .3 & Road Vehicle, Driver, Equipment \& Cargo Management \\
\hline 9.5 .4 & Freight Distribution \\
\hline 9.5 .5 & Inter-Modal Interface \\
\hline 9.5 .6 & Hazardous Goods Vehicle Management \\
\hline 9.5 .7 & Driver Rest Areas \\
\hline 9.5 .8 & Loading Zone Management \\
\hline
\end{tabular}

To fulfil these groups of User Need, FRAME/ARTIST offers a complete part in the Functional Architecture about goods management (8. Manage Freight and Fleet Operations). This area shall provide functionality to enable the management of Freight Transport and Logistic. It shall include the following function: 8.1 Manage Logistics and Freight; 8.2 Manage Commercial Fleet; 8.3 Manage vehicle/driver/cargo/equipment [9, 22].

The functions provide facilities for the management of freight and fleet operations in two situations. The first two functions (8.1 and 8.2) provide functionality for a static freight and fleet operations centre. This centre can accept goods (freight) for transportation from one location to another. The route will be chosen and this may involve the use of modes other than that provided by road transport. If necessary, the goods can be stored at points along the route to enable the most optimum scheduling to be used. The second function (8.2) can also manage the operation of a fleet of freight vehicles. This includes the scheduling and specification of drive duties and vehicle maintenance. The third function (8.3) provides functionality for the management of freight and fleet operations that are on-board a freight vehicle. It receives instructions about route plans and schedules and other information from the second function (8.2). It also provides that function with information about vehicle status, incidents and payments that have been made for things such as tolls [9, 22].

\section{The UIRNet's initiative}

UIRNet SpA was set up on the 2005 by the Italian Ministry of Infrastructure and Transport. Since 2005 the main freight villages and leading Italian companies have joined the UIRNet capital. Institutions and operator associations, with various contributions, also have joined the initiative, recognizing both its importance and UIRNet's network integrator capability.

Freight villages, named Interporti, connected to the UIRNet network, in particular, represent the main Italian logistic nodes involved in the freight 
multimodal transport and in the interchange of containers from road to rail mode and vice versa.

\subsection{Mission}

UIRNet mission is to improve for freight transport and logistics systems in Italy: efficiency, reliability, safety/security and sustainability.

These objectives are pursued to create a network among the complex world of transport and logistics operators through a pervasive use of integrated technology and network collaboration among actors, without introducing market changes prompted by current services and with no altering competition and treating all the operators equally. UIRNet aims also to assume the role of the logistics megacommunity integrator connecting every truck and logistic centre in the cloud managed by a public-private partnership.

The UIRNet focus is the realization of a peculiar National Logistic ITS Platform that integrates, in a innovative ICT infrastructure with an open and modular architecture, several technologies and a wide range of services (i.e. tracking \& tracing, freight transport planning and monitoring, hazardous goods management, advanced information about traffic and meteorological conditions, alert management, GIS, documents management, booking and marketplace, datawarehouse and reporting, etc.) to speed up the overall logistic process.

UIRNet aims to offer these services and solutions for the following types of operator: Hauliers and Transport Operators; Logistics Companies; Infrastructure (freight villages, ports, logistics centres, road network, etc.) Administrators; Institutions; Industries need transport; Producers; Data Analysts.

The PLN is in phase of completion of realization and it is in release phase of the basic and advanced system services. In parallel with the development, UIRNet has also carried out some tests, involving the main transport associations and some logistic nodes and is initiating the launch of new PLN's experimentations (see section 3.2).

To achieve the integration among technologies and stakeholders, the PLN aggregates all traffic information and mobility, and all information relevant to freight transport, gathered from reliable static and dynamic sources. The collection and distribution of this information is the basis for all services provided through the PLN, which aims to be a collector and provider of services, building a community of people ordered and highly integrated, empowering and benefiting of the services offered.

The PLN, held by the Ministry of Infrastructure and Transport (MIT), with all the national interest data collected by it, is managed on its behalf by UIRNet $\mathrm{SpA}$, the public body that is executor of the MIT.

UIRNet SpA coordinates, in cooperation with the MIT, the entire system in the public interest and realizes, with the collaboration of institutions, public agencies and infrastructure operators, the following service categories (public interest logic): Enabling Services; System Basic Services; System Advanced Services.

The data needed for the realization of System Services are also provided by Institutional Bodies (Ministry of the Interior, Ministry of Environment, Customs 
Agency, Transport Associations, Civil Protection, Managers transport infrastructure, etc..) that collaborate on the development and at the same time benefit from these services making their activities more efficient and safer.

The Customers benefit by the services delivered through the PLN; provide the data for enabling different services; do business within the community.

\subsection{Experimentations}

UIRNet has conducted several experimentations to test the capability of PLN in particular with respect to interoperability with legacy systems (Fleet Management Systems-FMS and proprietary systems of logistics nodes) and the management of data (positions, trip plans, alerts, etc.) exchanged with them.

The main Transport Associations and in particular some Italian major transport companies and the Genoa Port Authority (with which UIRNet has signed an agreement) were involved to do the following tests:

1. the equipping of 40 trucks with both the device owned by the Companies and UIRNet's device for a comparison test of the GPS positioning data;

2. the integration (through PLN's Middleware) of the FMSs owned by the Companies and PLN, for the exchange of position data and weather-traffic alerts;

3. the interoperability between the FMSs owned by the Companies, the PLN and the Genoa Port legacy system (e-Port), for the management of the trucks arrival announcement at the Genoa Port and the alerts related to documents and terminals status.

Other experimentations that will involve a greater number of Transport Companies and trucks, the Customs Agency and other Institutions, other Service Providers and OBUs producers, will be fielded soon.

\section{Conclusions and future development}

The UIRNet's initiative can produce significant benefits and potential savings, compared with a limited investment, encouraging new opportunities in journey planning and collecting information, distribution of information relating to road conditions, traffic, accidents, diversion due to accidents, monitoring of empty vehicles and those carrying hazardous goods and optimized management of haulage fleets assistance to drivers in ordinary conditions and in case of emergency. It will be possible to reap even greater benefits through improved use of the intermodal transport network. To this end the new technologies can contribute to improving both supply and services and to maintaining a complete view of the journey for the customer, crucial for guaranteeing the expansion of intermodal transport.

The conducted experimentations have shown the PLN capability to interoperate with several technologies and legacy systems, supporting the communications among involved actors: institutions, road transport companies and logistics operators. Further experimentations in the near future could investigate the PLN skills to handle different OBUs (On Board Units) and 
transport dimensions (e.g. city logistics, smart city). In a next paper, the main quantitative results of the experimentation will be presented.

Future project development, based on essentially strong, consolidated foundations, will help achieve important strategic objectives, growth and system integration, thereby taking full advantage of the present infrastructure.

This will provide benefits in terms of:

- Increased competitiveness through the development of intermodal transport, of freight villages in terms of interface and market positioning, integration with other logistics systems both at home and abroad;

- Safety improvement: UIRNet's initiative may be a point of reference for the legislator when regulating the transport of hazardous goods;

- Internationalization, in terms of integration with European and Asian intermodal centres, and integration possibly with other international logistics projects;

- Environmental impact through the development and management of intermodal freight and hazardous waste;

UIRNet PLN is only the first brick for a wider system. But UIRNet has the potential for becoming the point of reference for logistics development in Italy and a best practice for the Europe.

\section{References}

[1] Eurostat-European Commission (2011), Energy, transport and environment indicators, ISSN 1725-4566, http://ec.europa.eu/eurostat.

[2] ACI-Italian Automobile Club (2010), Number of vehicles registered within 31/12/2010. Data and Statistics. www.aci.it.

[3] Confetra, ATKearney (2011), La Logistica Italiana, 66a Assemblea Annuale Sessione Pubblica con il patrocinio della Camera di Commercio Roma, Roma, 1 febbraio 2011.

[4] Eurostat (2012), Modal split of freight transport. Statistics Database Tables by themes. http://epp.eurostat.ec.europa.eu.

[5] Russo F. (2005), Sistemi di trasporto merci. Approcci quantitativi per il supporto alle decisioni di pianificazione strategica tattica ed operativa a scala nazionale. Franco Angeli, Milano, ISBN: 9788846465238.

[6] Jung S., Wunderlich K., Toppen A. (2004), The Evaluation of Advanced Traveler Information Services (ATIS) Impacts on Truck Travel Time Reliability - Using the Simulated Yoked Study Concept. Technical Report, Sponsored by U.S. Federal Highway Administration, Contract No.: DTFH61-00-C-00001 Project No.: 0900610D-01, Department: J190.

[7] Russo F. and Quattrone A. (2010), ITS Sistemi di trasporto intelligenti. Elementi di base e applicazioni operative per il trasporto privato, per il trasporto pubblico, per il trasporto merci e la logistica. Franco Angeli, Milano, ISBN: 9788856830217.

[8] European Commission (2010), Directive 2010/40/EU of the European Parliament and of the council of 7 July 2010 on the framework for the 
deployment of Intelligent Transport Systems in the field of road transport and for interfaces with other modes of transport.

[9] European Commission (2011), E-FRAME: Extend FRAMEwork architecture for cooperative systems version V1.0. Www.frame-online.net

[10] European Commission (2011), Intelligent transport systems in action. Action plan and legal framework for the deployment of intelligent transport systems (ITS) in Europe.

[11] Cascetta, E., Nuzzolo, A., Russo, F., Vitetta, A. (1996) A new route choice logit model overcoming IIA problems: specification and some calibration results for interurban networks, Proceedings of the $13^{\text {th }}$ International Symposium on Transportation Traffic Theory, Jean-Baptiste Lesort ed., Pergamon Press.

[12] Ben Akiva, M., Bergman, M.J., Daly A.J., Ramaswamy, R. (1984) Modelling interurban route choice behaviour. In Proceedings of the $9^{\text {th }}$ International Symposium on Transportation and Traffic Theory, VNU Science Press, pp. 299-330.

[13] Cascetta, E. (2001), Transportation System Engineering. Theory and Methods, Kluwer Academic Publishers.

[14] Quattrone A. (2008), Path generation modelling: experimentation on Italian road freight transport, in Urban Transport XIV: Urban transport and the environment in the 21st century, Brebbia, C.A. (ed.), WIT Press, pp. 639648, ISBN 978-1-84564-123-8.

[15] Train, K. (2002) Discrete Choice Methods with Simulation. Cambridge University Press, Cambridge.

[16] Quattrone A. and Vitetta, A. (2011), Random and fuzzy utility models for road route choice, Transportation Research Part E: Logistics and Transportation Review, May 18.

[17] Russo F., Vitetta A., Quattrone A. (2007), Route choice modelling for freight transport at national level, Proceedings of the European Transport Conference, Strasbourg, France.

[18] Russo F. and Vitetta A. (2011), Reverse assignment: calibrating link cost functions and updating demand from traffic counts and time measurements, Inverse problems in science \& engineering, n. 19, 2011, pp. 921-950, ISSN: 1741-5977.

[19] Pekka L. and Johanna L. (2005), European Cross-Border Information System for Rail Freight-CroBIT. In Proceedings of the 12th World Congress on Intelligent Transport Systems. San Francisco California, United States: 06-10/11/2005. www.crobit.org

[20] Kuhla E. (2006), CroBIT: an information platform for European cargo railways. In Proceedings of the European Transport Conference, Strasbourg, France 18-20/09/2006. www.crobit.org

[21] Tanenbaum, A.S. (2010) Computer Networks, Prentice Hall, Upper Saddle River, NJ (Fifth Ed.).

[22] MIT-Ministry of Infrastructures and Transports (2003). ARTIST: ARchitettura Telematica Italiana per il Sistema dei Trasporti V1.0, Italy. 